\title{
Combatting Substandard and Counterfeit Medicines in the Nigerian Drug Market: How Industrial Pharmacists Can Rise Up to the Challenge
}

\author{
Melody Okereke, BPharm?; Ignatius Anukwu, BPharm, MPharm²; Sola Solarin, BPharm³; \\ Mazi Sam Ohuabunwa, BPharm, OFR, MON, FPSN ${ }^{4}$ \\ ${ }^{1}$ Faculty of Pharmaceutical Sciences, University of Ilorin, Kwara State, Nigeria; ${ }^{2}$ National Chairman, Association of Industrial \\ Pharmacists of Nigeria; ${ }^{3}$ President, Industrial Pharmacy Section of the International Pharmaceutical Federation; \\ ${ }^{4}$ President, Pharmaceutical Society of Nigeria
}

\begin{abstract}
Substandard and counterfeit medicines (SCMs) are a major public health threat in Africa. In Nigeria, the manufacture and distribution of substandard and counterfeit medicines in the drug market are booming, despite the efforts of law enforcement agencies to crack down on criminal syndicates over the years. The current situation has been exacerbated due to factors tied to unregulated open drug markets, lack of counterfeit detection technology, poor local pharmaceutical manufacturing capacity, and porous cross-border monitoring and surveillance systems. However, industrial pharmacists have a key role to play in combatting the production and circulation of SCMs in the Nigerian drug market. In this commentary, we examine the prevalence of SCMs in Nigeria and proffer feasible recommendations that industrial pharmacists can leverage to ensure its effective containment.
\end{abstract}

\section{Introduction}

Substandard and counterfeit medicines (SCMs) are a major public health threat in Africa. The World Health Organization (WHO) estimates that over 280,000 children die annually because of taking substandard medicines as treatment for pneumonia and malaria in sub-Saharan African countries [1]. There is no consensus on a common definition of substandard and counterfeit medicines as existing definitions differ by country. However, the definition by Ziance in 2008 stands out. Ziance defined counterfeit medicines as products deliberately and fraudulently produced and/or mislabeled with respect to identity and/or source to make it appear to be a genuine product [2]. Counterfeit medicines include drugs that contain no active pharmaceutical ingredient (API), an incorrect amount of $\mathrm{API}$, an inferior-quality $\mathrm{API}$, a wrong $\mathrm{API}$, contaminants, or repackaged expired products [2]. Some counterfeit medications may even be incorrectly formulated and produced in substandard conditions [2]. To further understand the extent of harm caused by substandard and counterfeit medicines, the scenario illustrated by Chambliss et al., 2012 [3] is worth exploring.

"Imagine that a patient is prescribed chemotherapy to treat a life-threatening tumor. A pharmacist dispenses the prescribed medication and counsels the patient without realizing that the tablets did not contain an active ingredient. In this scenario, not only is the patient not receiving the prescribed medication but the physician and pharmacist are evaluating treatment outcomes based on the patient's response to a placebo."

Corresponding author: Melody Okereke, BPharm

Faculty of Pharmaceutical Sciences, University of Ilorin

Kwara State, Nigeria

Email: melokereke30@gmail.com
In Nigeria, the manufacture and distribution of substandard and counterfeit medicines in the drug market is booming, despite the efforts of law enforcement agencies to crack down on criminal syndicates. Although adulteration, falsification, and illicit manufacture of drugs is not a new threat, recent advances in industrialization and commerce have exacerbated the complexity of the problem. While Nigeria has made tremendous progress in reducing the circulation of SCMs from $40 \%$ in 2001 to $17 \%$ in 2005 [4], this issue continues to be a major challenge, particularly with regard to medicines of great public health importance, such as antimalarial drugs. In 2011, $64 \%$ of antimalarials circulating in Nigeria were reported to be substandard [5]. The continued presence of highly unregulated open drug markets in Nigeria's major cities has been a major contributor to the prevalence of counterfeit drugs [6] where medicines are hawked and sold freely on street corners, bus stops, kiosks, and stalls [6]. In Nigeria and other countries, these markets are well-known as outlets and conduits for substandard and counterfeit medicines [6,7]. Notable open drug markets in Nigeria include those located in Kano (SabonGari market), Lagos (Idumota market), Onitsha (Head-bridge market) [6] while other not-so-known open drug markets are found in Abia (Ariaria Market, Aba) and Rivers (Mile 1 and Mile 3 markets). The Idumota market in Lagos has been described as one of the world's largest markets. Manufacturers sell directly to merchants at the market, who then export to other parts of West Africa and Central Africa [7]. Preventing counterfeit medicines from entering Nigeria is very difficult, partly because more than $70 \%$ of drugs in Nigeria are imported [8]; these are mainly from India and China, which are two of the world's biggest sources of counterfeit medicines [6]. Unfortunately, in Nigeria, detecting these counterfeit medicines is equally difficult, because many of them pass through the unregulated open drug markets, thereby creating opportunities for counterfeits and substandard medicines to enter the legitimate supply chain. Indeed, the open drug markets represent a major source of medicines to many licensed pharmacy outlets, 
hospitals, medicine wholesalers, and retailers in Nigeria [6]. As long as the open drug markets remain operational, combatting substandard and counterfeit medicines would be increasingly difficult.

Health Implications of Substandard and Counterfeit Medicines Unscrupulous businessmen and women involved in the illegal production, importation, and circulation of SCMs target medicines with a large volume of use for the treatment of diseases. Antibiotics, anti-diabetic agents, antihypertensives, antimalarials, and lifestyle drugs are among the medicines targeted [9]. Undoubtedly, the consumption of these SCMs can result in serious health implications. These health implications include:

- development of resistance (drug resistance or multidrug resistance or cross-resistance) which can invariably result in treatment failures and consequently, death

- increased out-of-pocket expenditure

- $\quad$ increased burden on the already-overburdened health system, and

- loss of confidence in the health system.

There have been several reported cases of poisoning in Nigeria due to SCMs as a result of contamination. In 2008, a catastrophic event happened in Nigeria in which several children developed acute kidney injury and later died as a result of consuming a supposed teething solution called "My Pikin" which was contaminated by the accidental or intentional addition of diethylene glycol (DEG) as a solvent instead of propylene glycol [10]. Similar events occurred when the same DEG was used instead of propylene glycol in South Africa in 1969 and Nigeria in 1990, resulting in 7 and 47 deaths respectively [10]. Also, an investigation on the quality of widely circulated metformin tablets in Nigeria in 2017 revealed that half of the tested medicines failed at least one pharmacopoeia test of bioequivalence [11].

\section{Roles of Industrial Pharmacists in Combatting SCMs}

As one of the drivers and key players of the Nigerian drug market, industrial pharmacists can employ several measures and tactical approaches towards combatting the production and circulation of SCMs in Nigeria. In the context of this commentary, industrial pharmacists are those practicing in the pharmaceutical industry either in drug manufacturing, quality control, regulatory affairs, research and development, and marketing. The following measures can be leveraged by industrial pharmacists to combat the manufacturing and circulation of substandard and counterfeit medicines in the Nigerian drug market:

\section{Reform and Regulation of the Drug Supply Chain}

Unregulated open drug markets in Nigeria have already been described as a major contributor to the prevalence of SCMs [6]. A major source of worry is that these unregulated and unlicensed open drug market dealers also supply medicines to some retail and wholesale pharmacies in the country, as well as some health agencies. This gives these uncontrolled and unlicensed drug sellers the opportunity to falsify and adulterate medicines in attempt to benefit at the expense of public health and lives. In the absence of an on-site counterfeit detection mechanism, there lies a huge tendency that these medicines if contaminated or adulterated can reach patients directly. In response to the increasing threat of SCMs in the Nigerian drug market, a guideline for National Drug Distribution was initiated in 2012 (and launched in 2015) by the Federal Ministry of Health to reform the country's drug supply chain [12]. However, implementation and enforcement have been ineffectual [10]. Through advocacy efforts at the national and regulatory levels, industrial pharmacists can liaise with key stakeholders, law enforcement agencies, and regulatory bodies to ensure proper implementation of this guideline with strict enforcement. This will help to ensure that all medicines in circulation are from a known and reliable source. Furthermore, it will also reduce the demand for medicines from the unregulated open drug markets by the general public.

\section{Adoption of Mobile Authentication Service (MAS)}

In 2010, the National Agency for Food and Drug Administration and Control (NAFDAC) introduced the NAFDAC Mobile Authentication Service (MAS). It empowers consumers to immediately authenticate a medicine for free by following three basic steps: (i) scratching the sticker on the product; (ii) submitting the unique pin to a short code and (iii) getting a response within seconds showing whether the product is genuine or not [10]. A recent study has revealed the wide acceptance of MAS by $53 \%$ of community pharmacies in Nigeria [13]. Thus, as the use and acceptability of MAS are generally feasible, industrial pharmacists can play a key role by:

- Educating fellow pharmacists at the community level, the public and their parent company to adopt this technology at a lower cost.

- Monitoring of counterfeit product alerts.

- Conducting various authentication tests to ensure product integrity.

- This cutting-edge technology should be also be adopted by all pharmaceutical manufacturing companies in Nigeria to ensure the use and public consumption of only safe and authentic medicines.

3. Boosting Local Pharmaceutical Manufacturing Capacity With over 115 registered pharmaceutical manufacturers [14], Nigeria still depends on other countries such as India and China for the supply of active pharmaceutical ingredients and excipients. There are concerns that this may create an opportunity for falsified medicines to enter into the legitimate drug supply chain as these countries have already been reported to be two of the world's biggest sources of counterfeit medicines [6]. Thus, industrial pharmacists have a role to play by strengthening and intensifying local manufacturing capacity to avoid foreign dependence which is a potential source of SCMs. Nonetheless, the pharmaceutical industry cannot survive in a country without an enabling environment. Strengthening the country's pharmaceutical 
manufacturing capacity will also require more investment, dedication, collective advocacy, and coordinated efforts by the government and private stakeholders.

4. Strengthening Cross-Border Monitoring and Surveillance In a bid to smuggle SCMs into the country, most foreign manufacturers particularly from India rebrand medicines to evade detection by custom officials at the country's borders and ports [15]. Between $2^{\text {nd }}$ and $19^{\text {th }}$ of August
2020, 33 containers of prohibited drugs worth N1.3 trillion (\$3.2 billion) were shipped into three different locations in Lagos where it is then redistributed illegally to other parts of Nigeria [15]. Industrial pharmacists at the regulatory level will need to strengthen policy and laws that regulate the importation of drugs at the various channels of entry. Prosecutions should be intensified and targeted at corrupt officials as well as smugglers, illegal distributors and buyers.

The figure below is an overview of how industrial pharmacists can ensure the containment of substandard and counterfeit medicines in Nigeria.

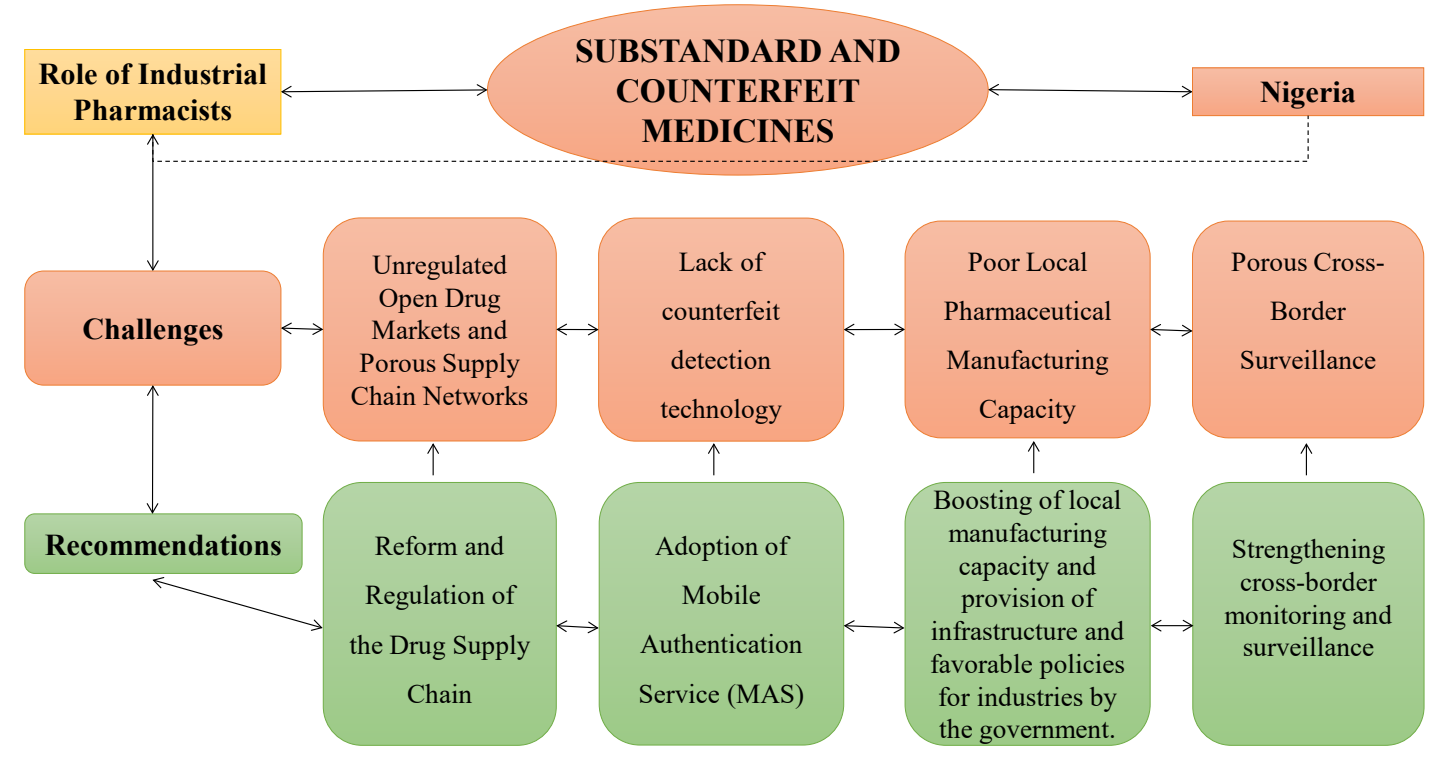

\section{Conclusion}

The production and circulation of substandard and counterfeit medicines (SCMs) in the Nigerian drug market is a dynamic and unquantifiable issue. The current situation has been exacerbated due to factors tied to unregulated open drug markets, lack of counterfeit detection technology, poor local manufacturing capacity, inconsistent regulatory oversight, poor monitoring and surveillance systems, and the lack of concerted anti-counterfeiting efforts by various national and multinational regulatory agencies. Although several strategies have been initiated to alleviate the burden of SCMs in Nigeria, industrial pharmacists must not relent in their efforts. They can play an active role in combating SCMs in the Nigerian drug market by reforming and regulating the drug supply chain, adopting Mobile Authentication Service (MAS), boosting local pharmaceutical manufacturing capacity and strengthening cross-border monitoring and surveillance.
Acknowledgements: The development of this commentary involved expert opinions, additions and recommendations from key stakeholders including the National Chairman, Association of Industrial Pharmacists of Nigeria (NAIP); President, Industrial Pharmacy Section of the International Pharmaceutical Federation (FIP-IPS), and the President, Pharmaceutical Society of Nigeria (PSN). Thus, this paper is intended to support policy and decision making in Nigeria and other countries that pursue similar offerings.

Funding: None

Conflicts of Interest: None 


\section{References}

1. World Health Organization (WHO). A study on the public health and socioeconomic impact of substandard and falsified medical products. https://www.who.int/medicines/regulation/ssffc/publicatio ns/SE Study EN.pdf?ua=1 Accessed June 20, 2021

2. Ziance RJ. Roles for pharmacy in combatting counterfeit drugs. J Am Pharm Assoc (2003). 2008;48(4):e71-e91. https://doi.org/10.1331/JAPhA.2008.07069

3. Chambliss WG, Carroll WA, Kennedy D, et al. Role of the pharmacist in preventing distribution of counterfeit medications. J Am Pharm Assoc (2003). 2012;52(2):195-199. https://doi.org/10.1331/JAPhA.2012.11085

4. World Health Organization-Regional Office for Africa. Sixtysixth session of the WHO Regional Committee for Africa. http://www.afro.who.int/en/sixty-sixth-session.html Accessed June 20, 2021

5. Beargie SM, Higgins CR, Evans DR, Laing SK, Erim D, Ozawa $S$. The economic impact of substandard and falsified antimalarial medications in Nigeria. PLoS One. 2019;14(8):e0217910. Published 2019 Aug 15. https://doi.org/10.1371/journal.pone.0217910

6. Chinwendu, O. (2008). The fight against fake drugs by NAFDAC in Nigeria.

https://digicollections.net/medicinedocs/documents/s1840 5en/s18405en.pdf Accessed June 20, 2021

7. Chukwuma, M. (2015). Book probes origin of fake drugs in Africa. http://guardian.ng/features/science/book-probesorigin-of-fake-drugs-in-africa/Accessed June 20, 2021

8. Fatokun O. Curbing the circulation of counterfeit medicines in Nigeria. Lancet. 2016;388(10060):2603. https://doi.org/10.1016/S0140-6736(16)32121-3
9. National Agency for Food and Drug Administration and Control (NAFDAC). Curbing Substandard, Falsified (SFS) And Counterfeit Medicines.

https://www.nafdac.gov.ng/curbing-substandard-falsifiedsfs-and-counterfeit-medicines/ Accessed June 2, 2021

10. Aminu N, Sha'aban A, Abubakar A, Gwarzo MS. Unveiling the peril of substandard and falsified medicines to public health and safety in Africa: Need for all-out war to end the menace. Medicine Access@ Point of Care. 2017;1:maapoc0000023. https://doi.org/10.5301\%2Fmaapoc.0000023

11. Buckley GJ, Gostin LO, Committee on Understanding the Global Public Health Implications of Substandard, Falsified, and Counterfeit Medical Products; Board on Global Health; Institute of Medicine, eds. Countering the Problem of Falsified and Substandard Drugs. Washington (DC): National Academies Press (US); May 20, 2013.

https://doi.org/10.17226/18272

12. Federal Ministry of Health. National Drug Distribution Guidelines. https://www.health.gov.ng/doc/NDDG.pdf Accessed June 2, 2021

13. Oyetunde OO, Ogidan O, Akinyemi MI, Ogunbameru AA, Asaolu OF. Mobile authentication service in Nigeria: An assessment of community pharmacists' acceptance and providers' views of successes and challenges of deployment. Pharm Pract (Granada). 2019;17(2):1449. https://doi.org/10.18549/PharmPract.2019.2.1449

14. Pharmaapproach. List of Pharmaceutical Companies in Nigeria. https://www.pharmapproach.com/list-ofpharmaceutical-companies-nigeria/Accessed June 2, 2021

15. Institute for Security Studies. Increased risk for Nigerians as drug smugglers rebrand Tramadol. https://issafrica.org/isstoday/increased-risk-for-nigerians-as-drug-smugglersrebrand-tramadol Accessed June 2, 2021 